\title{
Efficacy and Adverse Effects of Sofosbuvir plus Daclatasvir Therapy in Chronic HCV Patients in Sharkia Governorate, Egypt
}

\author{
Nahla E El-Gammal, MD, Noha E Shahin, MD \\ and Abeer H Abdelkader, MD \\ Tropical Medicine Department, Faculty of Medicine, Zagazig University, Zagazig, Egypt
}

Corresponding Author
Abeer H Abdelkader,
MD

Mobile:

$+201062537899$

E mail:

ab_alashry@yahoo.co

$m$

Key words:

Sofosbuvir;

Daclatasvir; Ribavirin;

Sustained virological response; Chronic hepatitis, Cirrhosis
Background and study aim: Hepatitis C is the most pressing public health challenge in Egypt with variable prevalence rates among different age groups. This study aimed to detect the efficacy and adverse effects of sofosbuvir plus daclatasvir therapy in treatment of chronic $\mathrm{HCV}$ patients in Sharkia governorate.

Patients and Methods: One hundred and ten patients were included in this study, divided into 4 groups; group I: 55 treatment naïve patients receiving (sofosbuvir + daclatasvir) for 12 weeks, group II: 36 treatment naïve patients receiving (sofosbuvir + daclatasvir + ribavirin) for 12 weeks, Group III: 9 treatment experienced patients receiving (sofosbuvir + daclatasvir + ribavirin) for 24 weeks and Group IV: 10 chronic HCV patients not receiving anti-viral therapy. Patients were followed by clinical and laboratory evaluation monthly during treatment and for 3 months after end of treatment. In addition, the virological response and adverse effects were reported.

Results: The rate of SVR response was equal in the three treated groups. There was statistically significant increase in nausea and headache in groups I and II while arthralgia, myalgia and fatigue were more frequent in group I. There was also statistically significant improvement in Child score among treated cirrhotic patients after treatment.

Conclusion: Daclatasvir plus sofosbuvir with or without ribavirin for 12 or 24 weeks is highly effective in treatment of naïve or experienced Egyptian $\mathrm{HCV}$ patients in Sharkia governorate. This combination is well tolerated in both cirrhotic and noncirrhotic patients with mild adverse effects.

\section{INTRODUCTION}

Hepatitis $\mathrm{C}$ is the most pressing public health challenge in Egypt. According WHO, Egypt has the highest prevalence of hepatitis $\mathrm{C}$ virus (HCV), where the results of blood screening and testing for the Egyptian blood donors showed $20 \%$ positivity for $\mathrm{HCV}$ antibody [1]. A published Egypt Health Issues Survey (EHIS) in 2015 on a nationally representative sample showed that $10 \%$ of Egyptians between 15 - 59 years of age had been infected with $\mathrm{HCV}$, while $7 \%$ are chronic active hepatitis C patients [2].

Sofosbuvir is a nucleotide analogue NS5B polymerase inhibitor approved by FDA in 2013, for the treatment of chronic $\mathrm{HCV}$ infection as a component of a combination antiviral treatment regimen. Sofosbuvir-based regimens provide a higher cure rate, fewer side effects, and a two- to four-fold reduced duration of therapy [3].

Daclatasvir is an HCV NS5A replication complex inhibitor that inhibits intracellular HCV RNA synthesis as well as inhibiting virion assembly and release. In vitro, daclatasvir demonstrated potent pangenotypic antiviral activity against HCV genotypes 1-6 [4].

This study aimed to compare the efficacy and safety of sofosbuvir + daclatasvir regimen with or without ribavirin in non-cirrhotic and cirrhotic naive and treatment experienced HCV patients in Sharkia governorate, Egypt. 


\section{PATIENTS AND METHODS}

This prospective cohort study was conducted in Tropical Medicine Department, Zagazig University Hospitals, Egypt during the period between May 2016 and February 2017. A total of one hundred and ten patients were included in this study.

\section{Inclusion criteria:}

Patients with chronic HCV infection evidenced by positive HCV RNA quantitative PCR with at least twice elevation of liver enzymes (more than 2 times upper limit of normal for the laboratory) in the previous 6 months with or without cirrhosis were included. Diagnosis of cirrhosis was based on combined clinical, laboratory and imaging data.

\section{Exclusion Criteria:}

Total serum bilirubin $>3 \mathrm{mg} / \mathrm{dl}$, Serum albumin $<2.8 \mathrm{gm} / \mathrm{dl}$, INR $\geq 1.7$, Platelet count $<50000 / \mathrm{mm}^{3}$, Intra or extahepatic malignancy, Pregnancy or inability to use effective contraceptive, Inadequately controlled diabetes mellitus ( $\mathrm{HbA} 1 \mathrm{c}$ $>9 \%$ ), Age below 18 years or over 75 years, Patients who didn't give consent to participate in the study, Patients with Child C cirrhosis.

The patients were divided according to National Committee for Control of Viral Hepatitis (NCCVH) protocol update on November 2015[5] into four groups:

- Group I: Fifty five treatment naïve patients treated by sofosbuvir $400 \mathrm{mg} /$ day +daclatasvir $60 \mathrm{mg} /$ day for 12 weeks.

- Group II: Thirty sex treatment naïve patients treated by sofosbuvir $400 \mathrm{mg}$ +daclatasvir 60 $\mathrm{mg} /$ day +ribavirin $600 \mathrm{mg} /$ day for 12 weeks.

- Group III: Nine treated experienced patients were retreated by sofosbuvir $400 \mathrm{mg} /$ day +daclatasvir $60 \mathrm{mg} /$ day +ribavirin $600 \mathrm{mg} /$ day for 24 weeks.

- Group IV: Ten chronic HCV patients matched for age, sex and Child classification as the treatment group and are not receiving antiviral therapy at the time of the study (control group).

\section{All patients were subjected to:}

- Full history taking, Thorough clinical examination

- Laboratory investigations: Complete blood picture (CBC), liver functions (S. bilirubin, SGOT, SGPT, total protein and S. albumin), coagulation profile (PT, INR), kidney function (S. creatinine), Viral markers ( HBsAg, HBc
IGM and HCV IgG), Alpha-feto protein ( $\alpha$ FP), Blood sugar,HBA1C for diabetics, HCV PCR for detection of HCV RNA.

- Abdominal ultra-Sonography (U/S): Ultrasound used for assessment of the liver, diagnosis of cirrhosis, detection of ascites and exclusion of hepatic focal lesions [6,7].

\section{Follow up:}

Patients were followed up through treatment by clinical evaluation, CBC, liver functions and kidney functions after 1 week and 2 weeks of treatment then every month till end of treatment and PCR for HCV RNA after 4 weeks, end of treatment (EOTR) and 3 months after stoppage of therapy. The primary efficacy end point was the percentage of patients in each group with sustained virological response (SVR), defined as HCV RNA < $15 \mathrm{IU} / \mathrm{mL} 12$ weeks after stoppage of treatment [8]. Patients in all groups were followed up monthly during treatment and for 3 months after end of treatment for any developed adverse effects with complete analysis including types, onset, course, duration, association, frequency, if the patient asked for medical advice, took any medications and if had been admitted to hospital for these side effects. Grading of these adverse effects was done according to the common terminology criteria of adverse events 2010[9].

\section{The Common Terminology Criteria for Adverse Events (CTCAE):}

A descriptive terminology which can be utilized for Adverse Event (AE) reporting. A grading (severity) scale is provided for each $\mathrm{AE}$ term.

CTCAE Terms: An Adverse Event (AE) is any unfavorable and unintended sign (including an abnormal laboratory finding), symptom, or disease temporally associated with the use of a medical treatment or procedure

Grades: Grade refers to the severity of the AE. The CTCAE displays Grades 1 through 5 with unique clinical descriptions of severity for each $\mathrm{AE}$ based on this general guideline:

- Grade 1 Mild; asymptomatic or mild symptoms; clinical or diagnostic observations only; intervention not indicated.

- Grade 2 Moderate; minimal, local or noninvasive intervention indicated; limiting ageappropriate instrumental activities of daily life (ADL).

- Grade 3 Severe or medically significant but not immediately life-threatening; hospitalization

El-Gammal et al., Afro-Egypt J Infect Endem Dis 2018; 8(4):174-181

https://aeji.journals.ekb.eg/

http://mis.zu.edu.eg/ajied/home.aspx 
or prolongation of hospitalization indicated; disabling; limiting self-care ADL.

- Grade 4 Life-threatening consequences; urgent intervention indicated.

- Grade 5 Death related to AE.

\section{End points}

The primary efficacy end point was SVR. The second end point is the development of treatment related side effects.

\section{Statistical analysis:}

The collected data were computerized and statistically analyzed using SPSS program (Statistical Package for Social Science) version 20.0.Chi-square test was used to examine the relation between qualitative variables. Quantitative data were expressed as mean \pm SD. Paired Anova and Kruskal wallis test were used to compare quantitative data and simple t test and Wilcoxon test were used to compare the changes before and after the course of treatment for parametric and non-parametric variables respectively . Significance was defined as $\mathrm{P}<0.05[\mathbf{1 0}]$.

\section{RESULTS}

\section{Study population}

This study included $110 \mathrm{HCV}$ patients from Sharkia governorate, Egypt. Their age ranged from 22 to 76 years old, 74 males $(67.3 \%)$ and 36 females (32.7\%), 74 patients were cirrhotic (67.3\%), 36 patients were non cirrhotic (32.7\%), 67 cirrhotic patients were child A $(90.5 \%)$ and 7 were child B.

The patients included in this study were treated according to the national Egyptian guidelines developed by NCCVH.

There were no significant differences in demographic,clinical,and sonographic findings among the studed groups at base line as shown in Table 1.

\section{Virological response}

The combination of sofobruvir/dacltasvir is very potent in treatment of $\mathrm{HCV}$ patients both cirrhotic and non cirrhotics with and without use of ribavirin for 12 or 24 weeks. This noticeable by achievement of $100 \%$ response both EOT and SVR. In this study as regard virological response for all treated patients (group 1, group 2 and group 3), there was negative PCR for HCV RNA at week 4 with $100 \%$ response in all treated patients which is still negative till end of treatment and 3 months after end of treatment.

\section{Biochemical and clinical paremeters}

It seems that sofosbruvir/daclatasvir regmins used in this study did not adversly affect the biochemical parameters used in routine practice (Table 2). CBC, liver enzymes, bilirubin and renal biochemistry did not show any significant change when baseline figure were comapred with figures during (data not shown) and after treatment.

Furthmore, all the treated crirhotic patients in this study showed clinical and biochemical benefits from sofobruvir/dacltasvir based rejiemns and this is reflected by improvements noticed in their Child scores by the end of treatment (Table 3).

\section{Adverse events}

As shown in Table 4, the combination of sofosbruvir/daclatasvir with or without RBV seems tolerable because there were no significant differences among the studied groups as regard all listed side effects. And when the side effects were graded into grades $(1,2,3$ as mild, moderate and severe respectively) according to CTCAE grading the reported side effects were mild (grade 1).

No serious or life threatning adverse events were reported. When the groups are viewed separately, nausea, headache, myalgia and arthralgia and fatigue were significantly higher at end of treatment than at beginning in group I. In group II only nausea and headache showed significant rise in the frequency by the end of treatment. In Group III no symptom had significant higher frequency by end of treatment. 
Table (1): Comparison of clinico-demographic findings among different groups

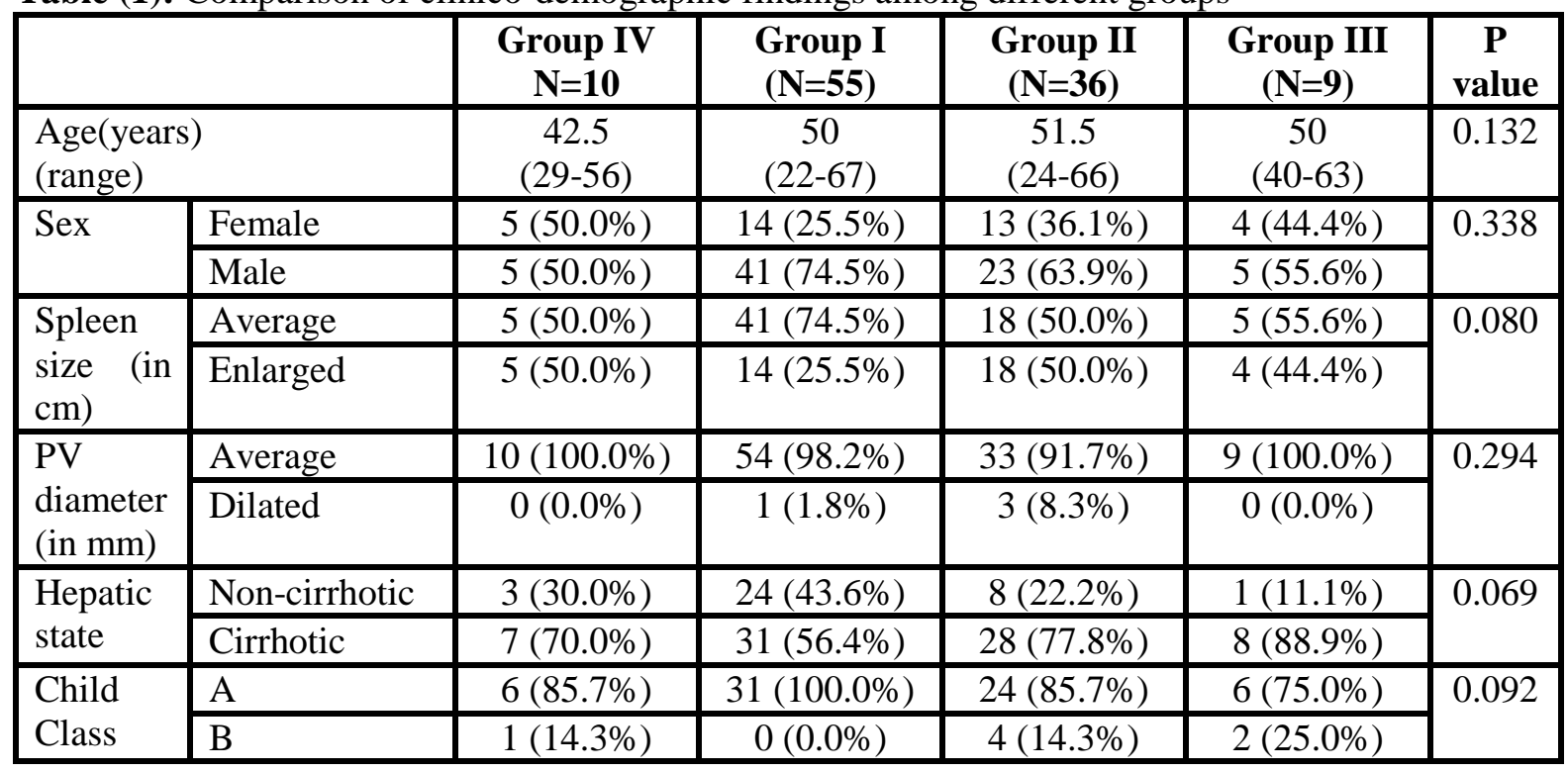

Table (2): Comparison between changes in laboratory parameters before and after treatment in the treated groups

\begin{tabular}{|l|c|c|c|c|}
\hline & $\begin{array}{c}\text { Group I } \\
(\mathbf{N}=\mathbf{5 5})\end{array}$ & $\begin{array}{c}\text { Group II } \\
(\mathbf{N}=\mathbf{3 6})\end{array}$ & $\begin{array}{c}\text { Group III } \\
(\mathbf{N = 9 9}\end{array}$ & P \\
\hline $\mathrm{Hb}, \mathrm{g} / \mathrm{dl}$ & $-1 \pm 1.5$ & $-01.2 \pm 1.7$ & $-1.1 \pm 1$ & 0.728 \\
\hline $\mathrm{PLT}, \mathrm{x} 109 \mathrm{~L}$ & $18.7 \pm 58$ & $33.3 \pm 57.3$ & $25.5 \pm 41.9$ & 0.442 \\
\hline $\mathrm{WBC}, \mathrm{x} 109 \mathrm{~L}$ & $0.1 \pm 2$ & $-0.1 \pm 2.2$ & $-0.8 \pm 1.8$ & 0.980 \\
\hline $\mathrm{Bil}, \mathrm{mg} / \mathrm{dl}$ & $-0.2 \pm 0.3$ & $0 \pm 0.4$ & $-0.7 \pm 0.1$ & 0.751 \\
\hline $\mathrm{Alb}, \mathrm{mg} / \mathrm{dl}$ & $0 \pm 0.5$ & $-0.1 \pm 0.5$ & $-0.5 \pm 0.6$ & 0.968 \\
\hline $\mathrm{INR}$ & $-0.1 \pm 0.1$ & $-0.1 \pm 0.2$ & $-0.2 \pm 0.1$ & 0.692 \\
\hline $\mathrm{AST}, \mathrm{IU} / \mathrm{l}$ & $-18 \pm 24.1$ & $-30.7 \pm 23.2$ & $-34.7 \pm 30.2$ & 0.798 \\
\hline $\mathrm{ALT}, \mathrm{IU} / \mathrm{l}$ & $-21 \pm 44.2$ & $-38.3 \pm 42.5$ & $-41.5 \pm 32.2$ & 0.487 \\
\hline $\mathrm{Cr}, \mathrm{mg} / \mathrm{dL}$ & $0 \pm 0.2$ & $0 \pm 0.2$ & $0 \pm 0.1$ & 0.755 \\
\hline
\end{tabular}

Table (3): Comparison between changes in Child score before and after treatment in the treated groups

\begin{tabular}{|l|c|c|c|}
\hline \multirow{2}{*}{} & \multicolumn{2}{|c|}{ Child score } & \multirow{2}{*}{ P value } \\
\cline { 2 - 3 } & $\begin{array}{c}\text { Baseline } \\
\text { Mean } \pm \text { SD }\end{array}$ & $\begin{array}{c}\text { EOT } \\
\text { Mean } \pm \text { SD }\end{array}$ & \\
\hline Group I (N=31) & $5.5 \pm 0.5$ & $5.4 \pm 0.5$ & 0.013 \\
\hline Group II (N=28) & $5.7 \pm 0.7$ & $5.5 \pm 0.5$ & 0.012 \\
\hline Group III (N=8) & $5.8 \pm 0.8$ & $5.2 \pm 0.4$ & 0.051 \\
\hline
\end{tabular}


Table(4): Frequency of Adverse Events in the studied groups during receiving treatment

\begin{tabular}{|l|c|c|c|c|c|}
\hline \multirow{2}{*}{ Adverse Events } & \multirow{2}{*}{$\begin{array}{c}\text { Group IV } \\
(\mathbf{N = 1 0})\end{array}$} & $\begin{array}{c}\text { Group I } \\
\mathbf{N = 5 5}\end{array}$ & $\begin{array}{c}\text { Group II } \\
\mathbf{N = 3 6}\end{array}$ & $\begin{array}{c}\text { Group III } \\
\mathbf{N = 9}\end{array}$ & \multirow{2}{*}{$\begin{array}{c}\text { P } \\
\text { Value }\end{array}$} \\
\hline Nausea & $2(20.0 \%)$ & $8(14.5 \%)$ & $11(30.6 \%)$ & $2(22.2 \%)$ & 0.190 \\
\hline Vomiting & $1(10.0 \%)$ & $4(7.3 \%)$ & $5(13.9 \%)$ & $0(0.0 \%)$ & 0.243 \\
\hline Constipation & $1(10.0 \%)$ & $3(5.5 \%)$ & $1(2.8 \%)$ & $1(11.1 \%)$ & 0.607 \\
\hline Diarrhea & $1(10.0 \%)$ & $1(1.8 \%)$ & $4(11.1 \%)$ & $1(11.1 \%)$ & 0.135 \\
\hline Dry mouth & $0(0.0 \%)$ & $3(5.5 \%)$ & $2(5.6 \%)$ & $1(11.1 \%)$ & 0.827 \\
\hline Dyspepsia & $3(30.0 \%)$ & $11(20.0 \%)$ & $7(19.4 \%)$ & $4(44.4 \%)$ & 0.286 \\
\hline Pruritus & $1(10.0 \%)$ & $3(5.5 \%)$ & $5(13.9 \%)$ & $2(22.2 \%)$ & 0.203 \\
\hline Headache & $3(30.0 \%)$ & $11(20.0 \%)$ & $10(27.8 \%)$ & $2(22.2 \%)$ & 0.692 \\
\hline Insomnia & $1(10.0 \%)$ & $5(9.1 \%)$ & $2(5.6 \%)$ & $1(11.1 \%)$ & 0.772 \\
\hline Depression & $0(0.0 \%)$ & $1(1.8 \%)$ & $0(0.0 \%)$ & $0(0.0 \%)$ & 0.548 \\
\hline Arthralgia & $2(20.0 \%)$ & $14(25.5 \%)$ & $7(19.4 \%)$ & $2(22.2 \%)$ & 0.797 \\
\hline Myalgia & $2(20.0 \%)$ & $14(25.5 \%)$ & $7(19.4 \%)$ & $2(22.2 \%)$ & 0.797 \\
\hline Bone pain & $1(10.0 \%)$ & $14(25.5 \%)$ & $6(16.7 \%)$ & $1(11.1 \%)$ & 0.433 \\
\hline Fatigue & $3(30.0 \%)$ & $16(29.1 \%)$ & $7(19.4 \%)$ & $3(33.3 \%)$ & 0.506 \\
\hline Cough & $2(20.0 \%)$ & $9(16.4 \%)$ & $4(11.1 \%)$ & $2(22.2 \%)$ & 0.647 \\
\hline Flu-like & $3(30.0 \%)$ & $10(18.2 \%)$ & $7(19.4 \%)$ & $3(33.3 \%)$ & 0.606 \\
\hline
\end{tabular}

Table (5): Comparison between grades of Adverse Events before and after treatment in the studied groups

\begin{tabular}{|c|c|c|c|c|c|c|c|c|c|c|}
\hline \multirow{2}{*}{$\begin{array}{l}\text { Adverse } \\
\text { Events }\end{array}$} & \multirow[t]{2}{*}{ Grade } & \multicolumn{2}{|c|}{$\begin{array}{c}\text { Group I } \\
N=55\end{array}$} & & \multicolumn{2}{|c|}{$\begin{array}{c}\text { Group II } \\
N=36\end{array}$} & & \multicolumn{2}{|c|}{$\begin{array}{c}\text { Group III } \\
\mathbf{N}=9\end{array}$} & \multirow{2}{*}{$\begin{array}{c}P \\
\text { value }\end{array}$} \\
\hline & & Baseline & EOT & & Baseline & EOT & & Baseline & EOT & \\
\hline Nausea & & & & & & & $\overline{0413}$ & & & 0.58 \\
\hline Headache & $\begin{array}{l}\text { Grade1 } \\
\text { Grade2 }\end{array}$ & $\begin{array}{l}1(1.8 \% \\
0(0 \%)\end{array}$ & & 0.0086 & & & $\begin{array}{l}0.0326 \\
\text { (s) }\end{array}$ & & & .21 \\
\hline$\overline{\text { Artl }}$ & & & & & & & 0.1586 & & & 0.513 \\
\hline$\overline{\mathrm{Mya}}$ & $\begin{array}{l}\text { Grade1 } \\
\text { Grade2 }\end{array}$ & $\begin{array}{l}2(3.6 \%) \\
0(0 \%)\end{array}$ & $\begin{array}{l}9(16.3 \%) \\
5(9.1 \%)\end{array}$ & $\begin{array}{l}0.0041 \\
\text { (s) }\end{array}$ & $\begin{array}{l}3(8.3 \%) \\
0(0 \%)\end{array}$ & $\begin{array}{l}6(16.6 \%) \\
1(2.8 \%)\end{array}$ & 0.3233 & $\begin{array}{l}2(22.2 \%) \\
0(0 \%)\end{array}$ & $\begin{array}{l}0(0 \%) \\
2(22.2 \%)\end{array}$ & 0.13 \\
\hline$\because$ & $\begin{array}{l}\text { Srade1 } \\
\text { Srade2 }\end{array}$ & $\begin{array}{l}4(7.2 \%) \\
0(0 \%)\end{array}$ & $\begin{array}{l}10(18.1 \%) \\
6(10.9 \%)\end{array}$ & $\begin{array}{l}0.0062 \\
\text { (s) }\end{array}$ & $\begin{array}{l}4(11.1 \% \\
0(0 \%)\end{array}$ & $\begin{array}{l}6(16.6 \%) \\
1(2.8 \%)\end{array}$ & $\rho_{1}$ & $\begin{array}{l}1(11.1 \% \\
0(0 \%)\end{array}$ & $\begin{array}{l}1(11.1 \%) \\
2(22.2 \%)\end{array}$ & 0. \\
\hline
\end{tabular}

EOT: end of treatment. Grade 1: mild symptoms; clinical or diagnostic observations only; intervention not indicated. Grade 2: Moderate; minimal, local or noninvasive intervention indicated; limiting age-appropriate instrumental activities of daily life (ADL).

\section{DISCUSSION}

Based on data from the 2015 Egyptian Health Issue Survey [EHIS], approximately 3.7 million persons in Egypt were estimated to have $\mathrm{HCV}$ viremia [2]. In Egypt most of our infections are due to difficult to treat genotypes with genotype 4 is the prevalent one and also genotype 1 occurs in some patients and that is why potent antiviral regimens are needed to eliminate the infection [11].
Following approval of sofosbuvir as a backbone in treatment regimen of $\mathrm{HCV}$ and in November 2015 NCCVH protocol was updated to add new regimens in $\mathrm{HCV}$ treatment including daclatasvir in combination with sofosbuvir with or without ribavirin, ledipasvir in single tablet with sofosbuvir with or without ribavirin and Paritaprevir/ ritonavir/ ombitasvir with or without ribavirin [5] and the local industry was licensed to manufacture generic products of the potent antivirals including sofosbuvir and daclatasvir at affordable prices and that is why they were used in this study. 
In our study there was male predominance highlighted the high exposure rate and characteristics of the blood donor population who are presumably healthy adult males who seek medical assistance after being diagnosed in blood banks. A similar male predominance was reported by Gad et al. [12] and Mabrouk et al. [13].

The $100 \%$ SVR reported in our study re-enforces the potency of sofosbuvir/daclatasvir combination therapy and is in agreement with Wyles et al. [14] who found that treatment naïve and treatment experienced patients with HCV genotype 3 or 4 infection who received daclatasvir plus sofosbuvir for 12 weeks, the SVR 12 rate was $100 \%$.

These results were also similar to that reported by EASL which found that combination of sofosbuvir and daclatasvir in patients genotype 1 without cirrhosis with 24 weeks of therapy, the SVR rates were $100 \%$ (14/14 and 15/15, without and with ribavirin, respectively) in treatment-naïve patients, and 100\% (21/21) and 95\% (19/21) without and with ribavirin, respectively, in patients who did not respond to the combination of pegylated IFN-a, ribavirin, and either telaprevir or boceprevir. With 12 weeks of therapy, SVR was achieved in 98\% (40/41) of treatment-naïve patients without ribavirin [8].

In addition Leroy et al. [15] detected that chronic $\mathrm{HCV}$ genotype 3 receiving sofobuvir and daclatasvir plus ribavirin for 12 weeks, the SVR 12 weeks was $100 \%$ in patients with advanced fibrosis, SVR 12 was $86 \%$ in patients with cirrhosis and SVR 12 was $87 \%$ in patients with treatment experienced. This difference may be due to selection criteria as most of our patients were Child A and difference in HCV genotyping because most of Egyptian patients are genotype 4 and that is why in Egypt genotyping is not routinely performed before initiation of anti-viral therapy.

Many clinical side effects were detected during treatment of our patients. However, most of adverse effects were of grade 1 severity and some of grade 2 severity according to the CTCAE grading. Adverse effects were mild without intervention or affection of the daily activity or quality of life. Furthermore, no serious adverse events were detected and no patient stopped treatment due to side effects with $100 \%$ compliance rate.

The most commonly reported adverse events were fatigue, bone pain, myalgia and headache. Frequency of all adverse events was not statistically significant between the studied groups. The frequency of reported side effects were not different from those reported in the literature and were found in agreement with Landis et al. [16] and Hezode et al. [17] who found that headache affects $(18.5 \%)$ of daclatasvir plus sofosbuvir recipients versus $(27.2 \%)$ of daclatasvir plus sofosbuvir and ribavirin and fatigue affect $2.8 \%$ and $15.3 \%$ respectively. Also, EASL reported that the most common adverse reactions are fatigue, headache and nausea among daclatasvir plus sofosbuvir recipients. When sofosbuvir and daclatasvir were administered with ribavirin, the most frequent adverse drug reactions were consistent with the known safety profile of ribavirin [8].

Another review by Keating [18] reported that the majority of adverse events were of mild to moderate severity. The most commonly reported adverse events were headache $18.5 \%$ of daclatasvir plus sofosbuvir recipients and $27.2 \%$ of daclatasvir plus sofosbuvir and ribavirin recipients, nausea $(14.4 \%$ and $15.8 \%)$ and fatigue $(2.8 \%$ and $15.3 \%)$. A similar tolerability profile was seen in patients with or without cirrhosis who received daclatasvir plus sofosbuvir and daclatasvir plus sofosbuvir and ribavirin that was also generally well tolerated in patients with chronic $\mathrm{HCV}$ genotype 1 or 3 infection and post-transplant recurrence and this is consistent.

Also, Paul et al. [19] who reported that daclatasvir plus sofosbuvir ( \pm ribavirin) was well tolerated in clinical trials with no treatment-related deaths, discontinuations as a result of adverse events or treatment-related serious adverse events were reported. Across these trials, adverse events reported in these trial were headache more than $10 \%$ of patients included $(20 \%$ and $24 \%$ of patients in ALLY-3 and ALLY-3+ respectively), fatigue (19\% and $26 \%$ ), nausea (12\% and not reported) and insomnia (6\% and $30 \%)$.

In addition to the excellent antiviral activity (100\% SVR) and accepted safety profile (mild adverse events) of Daclatasvir/sofosbuvir regimen in treatment of our cohort with $\mathrm{HCV}$, the biochemical parameters and clinical items were also improved and this noticed in improvements of the Child scores reported after the end of treatment. These improvements of biochemical and clinical parameters were also reported by other authors from the local Egyptian community [20-22] and by international authors [23].

When also viewed from the economic side with affordable price in the Egyptian market the 
combination of Daclatasvir/sofosbuvir is prioritized in treatment of or Egyptian patients.

Our study has limitations: first; patients were followed up for 3 months after the end of treatment, so cannot detect any relapse if it developed. Second; this is one center study . Third; small numbers of patients.

In Conclusion Daclatasvir plus sofosbuvir with or without ribavirin for 12 or 24 weeks is highly effective in treatment of naïve or experienced Egyptian patients with or without cirrhosis with SVR rates of $100 \%$. Daclatasvir plus sofosbuvir with or without ribavirin for 12 or 24 weeks is tolerable in both cirrhotic and non cirrhotic patients with mild adverse effects.

\section{Ethical consideration:}

Ethical approval was obtained from the Committee of Research, Publications and Ethics of the college of Medicine, Zagazig University, Egypt. All procedures were explained to patients and a written or thumb-printed informed consent was obtained

\section{Funding:None. \\ Conflict of interest: None.}

\section{REFERENCES}

1. WHO. Guidelines for the screening, care and treatment of persons with hepatitis $\mathrm{C}$ infection 2016."http://www.who.int/hepatitis/publications/ hepatitis-c-guidelines-2016/en/

2. Ministry of Health and Population [Egypt], ElZanaty and Associates [Egypt], ICF International. Egypt Health Issues Survey 2015. Cairo, Rockville, MD: Ministry of Health and Population, ICF International; 2015.

3. Keating $\mathrm{G}$ and Vaidya A Sofosbuvir: first global approval. Drug 2014 Feb;74 (2):273-82.

4. Smith MA, Regal RE and Mohammad RA. Daclatasvir: a NS5A replication complex inhibitor for hepatitis C infection. Ann pharmacother 2016; 50(1):39-46.

5. National Committee for Control of Viral Hepatitis (NCCVH) Protocol (2015a):http://www.nccvh. net/ doctorsInformationDetails/L5A9E3DX8Rw=

6. Bluth EI, Ultrasound, a practical approach to clinical problems. Thieme Publishing Group 2008. ISBN: 3131168323.

7. McGahan J and Goldberg B. Diagnostic ultrasound. Informa Health Care .2008; ISBN: 1420069780.

8. EASL (2016):"Recommendations on Treatment of Hepatitis C "J ; Hep.2016

9. Common Terminology Criteria for Adverse Events (CTCAE) (2010) https://evs.nci.nih.gov/ ftp1/CTCAE/ CTCAE_4.03_2010-06 14_Quick Reference_5x7.pdf.
10. Elliott AC \& Woodward WA, Statistical analysis quick reference guidebook: With SPSS examples 2007.

11. Abdel-Aziz F, Habib M, Mohamed M, Gamil F, Madkour S, Mikhail NN, et al., Hepatitis C virus (HCV) infection in a community in the Nile Delta: population description and $\mathrm{HCV}$ prevalence. Hepatology 2000; 32: 111-115.

12. Gad R, Males S, El-Makhzangy H, Shouman S, Hasan A, Attala M, et al., Predictors of a sustained virological response in patients with genotype 4 chronic hepatitis C. Liver Int. 2008, 28(8) : 1112-1119.

13. Mabrouk M, El-Raziky M, Zayed N, Salama R, El-Akel W, Awad T et al., Clinical, biochemical and pathological profiles of 5464 Egyptian chronic hepatitis C-infected patients. Hepatogastroenterology 2013; 60(127):1731-1735.

14. Wyles D, Ruane P, Sulkowski M, Dieterich D, Luetkemeyer A, Morgan TR et al., Daclatasvir plus Sofosbuvir for HCV in Patients Coinfected with HIV-1. N Engl J Med 2015; 20; 373(8):71425.

15. LeroyV, Angus P, Bronowicki JP, Dore GJ, Hezode C, Pianko $\mathrm{S}$ et al., Daclatasvir, sofosbuvir, and ribavirin for hepatitis $\mathrm{C}$ virus genotype 3 and advanced liver disease: A randomized phase III study (ALLY-3+). Hepatology. 2016; 63:1430-41.

16. Charles S. Landis, David R. Nelson, Mark S. Sulkowski, et al., An integrated safety analysis of daclatasvir plus sofosbuvir, with or without ribavirin, in patients with chronic HCV infection [abstract no. 716 plus poster]. Hepatology. 2015;62(1 Suppl):565A.

17. Hezode C, Dore GI, Pianko S, Pol S, Stuart K ,Thompson A, et al., Daclatasvir plus sofosbuvir plus ribavirin for 12 or 16 weeks in treatmentexperienced patients with HCV genotype 3 infection and advanced fibrosis or cirrhosis. $J$ Hepatol. 2016; 64(Suppl 2):S753-4.

18. Keating G. Daclatasvir: A Review in Chronic Hepatitis C. Drugs 2016; Sep;76(14):1381-91.

19. Paul L, McCormacK, Katherine A and LysengWilliamso. Daclatasvir in hepatitis C virus infection: a guide to its use in the EU. Drugs. Ther Perspect $2016 ; 32: 42-49$.

20. Shiha G1, Soliman R, ElBasiony M, Hassan AA, Mikhail NN. Sofosbuvir plus Daclatasvir with or with out ribavirin for treatment of chronic $\mathrm{HCV}$ genotype 4patients: real-life experience. Hepatol Int. $2018 \mathrm{Jul} ; 12(4): 339-347$.

21. Abdel-Aziz AM, Ibrahim MA, El-Sheikh AA, Kamel MY, Zenhom NM, Abdel-Raheim S, Abdelhaleem H. Effect of Sofosbuvir Plus Daclatasvir in Hepatitis C Virus Genotype4 Patients : Promising Effect on Liver Fibrosis. J Clin Exp Hepatol. 2018 Mar;8(1):15-22. 
22. Abdel-Moneim A, Aboud A, Abdel-Gabaar M, Zanaty MI, Ramadan M. Efficacy and safety of sofosbuvir plus daclatasvir with or without ribavirin: large real-life results of patients with chronic hepatitis C genotype 4. Hepatol Int. 2018 May 12.
23. Babatin MA, Alghamdi AS, Albenmousa A, Alaseeri A, Aljarodi M, Albiladi H et al. Efficacy and safety of simeprevir or daclatasvir in combination with sofosbuvir for the treatment of hepatitis C genotype 4 infection. $J$ Clin Gastroenterol 2018 May/Jun; 52(5):452-457. 